\title{
¿ESTAS NO SON GUACAS TAMBIEN, COMO LAS NUESTRAS? IMAGEN DE CULTO Y EVANGELIZACIÓN EN EL SUR ANDINO *
}

¿Estas no son Guacas Tambien, como las Nuestras? Cult Image and Evangelization in the Southern Andes

Federico Aguirre **

RESUMEN: El presente artículo busca establecer el vínculo entre el culto prehispánico a las huacas y el surgimiento de la imagen de culto latinoamericana. Aun cuando la empresa conquistadora intentó erradicar la sensibilidad religiosa de los pueblos prehispánicos, esta pervivió y contribuyó al proceso de inculturación del evangelio en Latinoamérica. En este sentido, la imagen sin alma que trajo el conquistador, se termina convirtiendo en una imagen que habla con su pueblo, reivindicando la función sacramental de la imagen cristiana prerrenacentista. A partir del concepto antropológico de "agencia", plantearemos la huaca andina como antecedente de la imagen de culto latinoamericana, intentando, a su vez, explicitar los fundamentos teológicos de la función sacramental que asume la imagen en este caso. De este modo, sostenemos que la huaca andina es una semilla del verbo en la que florece el anuncio del evangelio.

PALABRAS CLAVE: Huaca. Imagen de culto. Teoría antropológica de la agencia. Teología de la imagen.

ABSTRACT: This article seeks to establish the link between the pre-Hispanic cult of the Huacas and the emergence of the Latin American cult image. Even when the conquerors tried to eradicate the religious sensitivity of the pre-Hispanic peoples,

\footnotetext{
* El presente artículo forma parte de la investigación postdoctoral titulada "Hacia una teología ecuménica de la imagen. Estudio comparativo sobre la función estético-sacramental de la imagen de culto en el contexto del cristianismo oriental y el cristianismo latinoamericano", patrocinada por el Instituto de Investigaciones Teológicas (ININTE) de la Pontificia Universidad Católica Argentina.

** Facultad de Teología de la Pontificia Universidad Católica de Chile, Santiago, Chile.
} 
it survived and contributed to the process of inculturation of the gospel in Latin America. In this sense, the image without a soul brought by the conqueror, ends up becoming an image that speaks to the people, claiming the sacramental function of the pre-Renaissance Christian image. Based on the anthropological concept of "agency", we will propose the Andean huaca as a predecessor of the Latin American cult image, trying to make explicit the theological foundations of the sacramental function assumed by the image in this case.

KEYWORDS: Huaca. Cult Image. Anthropological Theory of Agency. Theology of the Image.

\section{Introducción}

T a frase que encabeza el título de este artículo habría sido la pregunta Ldirigida por un indio a un cura doctrinero, al percatarse de que los cristianos, al igual que los indios, también veneraban objetos materiales como sus huacas:

Mas decirme eys, Padre, como nos dezis que no adoremos ydolos, ni guacas pues los christianos adoran las ymagenes que estan pintadas y hechas de palo, o metal, y las besan, y se hincan de rodillas delante dellas, y se dan en los pechos y hablan con ellas? Estas no son guacas tambien, como las nuestras? (SIRACUSANO, 2005, p. 273)

El supuesto diálogo se encuentra en un documento elaborado por la Diócesis de Lima en 1585 en el marco de los llamados Concilios Limenses, cuyo fin principal fue la extirpación de las prácticas religiosas prehispánicas ${ }^{1}$. Así, más que para entablar un diálogo, la pregunta del indio es empleada en dicho documento para poner en evidencia su equivocación, procediéndose a establecer la diferencia taxativa entre el ídolo prehispánico y la imagen de culto cristiana:

Hijos mios muy differente cosa es lo que hazen los Christianos, y lo que hazeis vosotros. Los Christianos no adoran ni besan las ymagenes por lo que son, ni adoran aquel palo o metal, o pintura, mas adoran a Iesu Christo en la ymagen del Crucifijo, y a la madre de Dios nuestra Señora la Virgen Maria en su imagen, y a los sanctos tambien en sus ymagenes, y bien saben los Christianos que Iesu Christo y nuestra Señora y los Sanctos estan en el Cielo vivos y gloriosos y no estan en aquellos bultos o ymagenes sino solamente pintados. (SIRACUSANO, 2005, p. 273)

Más allá de si efectivamente la doctrina cristiana de la imagen se reduce a lo señalado aquí -asunto que examinaremos más adelante-, el documento en cuestión denota la voluntad de dominación que marcó la evangelización

\footnotetext{
${ }^{1}$ Sobre el contenido de los denominados “Concilios Limenses" véase Castro (2009, p. 30-37).
} 
en América, en cuyo contexto la identificación de las huacas andinas con ídolos demoniacos sirvió de pretexto para el expolio y la explotación: los encomenderos tenían derecho a castigar severamente y hacerse de las tierras de aquellos que eran sorprendidos rindiendo culto a las huacas ${ }^{2}$. Salvo contadas excepciones como Bartolomé de Las Casas en México o Fray Domingo de Santo Tomás en Perú, el término "idolatría" es empleado de manera genérica durante la Colonia para identificar la heterodoxia cultural de los pueblos conquistados, donde la religión se constituirá en una poderosa herramienta de colonización (CASTRO, 2009, p. 23; MILLONES, 1998, p. 18).

Hoy, a la luz de los hallazgos de la etnohistoria y del desarrollo de antropologías descentralizadas, ha quedado en evidencia que términos como "idolatría", "magia" o "animismo" han operado como conceptualizaciones equívocas, que la mayoría de las veces pretenden, paradójicamente, definir lo que no se conoce ${ }^{3}$. A este respecto, es notable la temprana crítica que hace Ludwig Wittgenstein a la Rama dorada de James Frazer, de quien declara: “QQué estrecha la vida espiritual de Frazer! Debido a ello: qué imposibilidad de comprender otra vida que la inglesa de su tiempo. Frazer no puede imaginarse un sacerdote que no sea, en el fondo, un párroco inglés de nuestro tiempo con toda su estupidez y laxitud." (WITTGENSTEIN, 2016, p. 35).

Así como para las ciencias sociales ha sido un auténtico descubrimiento la existencia de civilización en culturas no occidentales, también para la teología católica ha significado un enriquecimiento descubrir la acción de Dios más allá de los límites institucionales de la Iglesia, y reconocer que las culturas prehispánicas tuvieron un rol activo en la inculturación del evangelio en estas latitudes ${ }^{4}$. Es más, esto se ha convertido en un imperativo a la hora de comprender los dones dispensados por el Espíritu en nuestro continente, más allá del empleo utilitario de la religión en el marco de la empresa colonizadora. A partir del impulso del Concilio Vaticano II y, en específico, de documentos como Evangelii Nuntiandi (1975) o las declaraciones emanadas de los encuentros del CELAM, han florecido las denominadas "teologías contextuales" en Latinoamérica, algunas de las cuales justamente buscan sacar a la luz las raíces indígenas de la fe cristiana de nuestro continente ${ }^{5}$.

El presente artículo se propone ahondar en la función sacramental que termina asumiendo la imagen de culto en Latinoamérica, a pesar de los intentos iniciales de las autoridades eclesiásticas y civiles de aplacar aquel

\footnotetext{
${ }^{2}$ No hay que olvidar que algunas huacas eran objetos de oro y plata que, luego de ser requisados, pasaban a engrosar las arcas de la Corona española (MILLONES, 1998, p. 19).

${ }^{3}$ Véase Morgan (2018), Gell (2016), Allen (2015).

${ }^{4}$ Véase NA, n. 2, GS, n. 92, FT, n. 274 y 277.

${ }^{5}$ Sobre las teologías contextuales, véase Fernández (2020, p. 203-263). Para las culturas andinas en particular, véase Irarrázabal (1999), Caram (2012), Tomichá (2013), Codina (2019).
} 
poder que el pueblo reconoce en la imagen ${ }^{6}$. Como ya hemos planteado en anteriores trabajos, esta función sacramental de la imagen goza de sólidos fundamentos dogmáticos en la tradición cristiana, establecidos en el marco de la querella iconoclasta entre los siglos VIII y IX, y especialmente estudiados en el campo de la teología del oriente cristiano (AGUIRRE, 2021; 2018). Como es sabido, en el ámbito latino, la imagen de culto irá perdiendo progresivamente -sin negarla nunca, no obstante- su potencia sacramental, proceso que comienza con el surgimiento de la teología carolingia y encuentra un momento culminante en la aparición de la obra de arte moderna en el Renacimiento (BELTING, 2009; GUARDINI, 1960).

En este sentido, llama la atención que la imagen sin alma del conquistador se haya convertido en una imagen que habla con su pueblo. Pese a los intentos de extirpar los objetos y prácticas religiosas de los indios, parece bastante verosímil que la imagen de culto latinoamericana, que reivindica la función sacramental de la imagen cristiana prerrenacentista, fuera fruto de la inseminación del poder que el indio reconocía en la huaca en la imagen inanimada que trajo el conquistador (SIRACUSANO, 2005, p. 13) ${ }^{7}$. El hecho de poseer una sensibilidad religiosa que se manifestaba en cada rincón de la creación junto con la astuta negociación que permitió traspasar esa sensibilidad a la imagen cristiana condujo al surgimiento de la imagen de culto latinoamericana, que hasta nuestros días anima las fiestas religiosas que se celebran en todo nuestro continente. De modo análogo, la imagen de culto bizantina es heredera del numen de las estatuas griegas (BELTING, 2009, p. 45-192).

En lo que sigue, desarrollaremos un análisis de la huaca andina a la luz de la teoría de la agencia, en vistas de comprender la sensibilidad religiosa de los pueblos andinos más allá de su caracterización como idolatría. A partir de aquí, intentaremos establecer el vínculo del culto prehispánico a las huacas con el surgimiento de la imagen de culto latinoamericana, la cual, como se ha indicado, reivindica la función sacramental de la imagen de culto cristiana prerrenacentista.

\section{La huaca prehispánica: lugar de agencia de lo sagrado}

La palabra "huaca" designa una serie de objetos, animales, hitos naturales, etc., que son considerados sagrados en el mundo andino. En estos

\footnotetext{
6 "La fuerza de la imagen en América Latina tiene mucho que ver con una lógica latinoamericana que más allá de los procesos de ruptura y desintegración ha tendido a construir y reconstruir nuevas síntesis, aún desde los desechos, para elevar y reconciliar" (CAAMAÑO, 2015, p. 118).

7 "De cara a la imagen la fe popular provoca la inculturación en sentido estricto, no como dinámica impuesta y ejercida desde fuera, sino como movimiento interno del pueblo creyente que se adhiere a Dios en su / desde su / historia" (CAAMAÑO, 2015, p. 117).
} 
se reconocen características extraordinarias y un poder sobrenatural, así como la posibilidad de constituirse en oráculos, es decir, comunicar la voluntad de la divinidad (ALLEN, 2015, p. 37; MILLONES, 1998, p. 16). Es importante subrayar que la huaca siempre se identifica con un objeto material concreto: una piedra, un pájaro, una estatuilla, un cerro, un cuerpo momificado, los cuales detentan en sí mismos la presencia de la divinidad. Su sacralidad, pues, no está asociada meramente a una idea de lo sagrado, sino al poder que emana de estas cosas materiales, poder capaz de intervenir y transformar la realidad y las relaciones sociales. En otras palabras, no se trata de símbolos que representan un significado abstracto o algo que no está en ellos, sino de índices en los que se hace presente una determinada agencia (ALLEN, 2015, p. 28-32).

La teoría antropológica de la agencia ha aportado una clave fundamental para comprender cómo operan aquellos objetos religiosos que de manera genérica son catalogados como "ídolos", destacando que en cada cultura cumplen diferentes funciones y poniendo de relieve que el hecho de atribuir intenciones a animales $\mathrm{u}$ objetos inanimados en ningún caso constituye indicador de una mentalidad primitiva sino, más bien, denota una característica fundamental de la sociabilidad humana ${ }^{8}$. Por otro lado, en el marco de esta teoría, se subraya que la agencia solo se hace perceptible en objetos materiales catalogados como "índices", es decir, un "signo natural" cuyo significado, a diferencia de un "signo convencional", únicamente es comprensible de manera performativa9. En este sentido, mientras que un símbolo representa algo que no es él, asignándosele convencionalmente un determinado significado, el índice ejecuta aquello que significa, reivindicando una relación causal con su significado.

La historiadora Gabriela Siracusano destaca que "la sacralidad andina se instalaba sobre objetos difíciles de discernir a primera vista, cuya 'carga de poder' parecía deslizarse por un terreno diferente al que los horizontes de expectativas de los evangelizadores les permitían imaginar" (SIRACUSANO, 2005, p. 268). Es por esta razón, como hemos señalado, que las huacas son catalogadas por los conquistadores como ídolos, término que en el contexto

\footnotetext{
8 “En una relación social, el 'otro' inmediato no tiene por qué ser 'humano'. En efecto, mi teoría depende por completo de que no lo sea. La agencia social se puede ejercer sobre las 'cosas', y la pueden ejercer las 'cosas' mismas, así como los animales" (GELL, 2016, p. 49). Alfred Gell ilustra su teoría con multitud de ejemplos que van desde la relación que establece un niño con su muñeco predilecto, una persona que le pone nombre a su vehículo o que maldice un artefacto cuando no funciona, hasta el mercado del arte, que invierte grandes sumas de dinero para exponer "un Van Gogh" o "un Cézanne".

9 "Una veleta es un índice de la dirección del viento: en primer lugar, porque toma la misma dirección del viento, de modo que existe una real conexión entre ambos; y, en segundo lugar, estamos constituidos de tal manera que el movimiento de la veleta en determinada dirección atrae nuestra atención hacia esa dirección; y cuando vemos que gira siguiendo las variaciones del viento, estamos forzados por las leyes de la mente a pensar que esa dirección está conectada con el viento" (PEIRCE, 1986, p. 50-51). Sobre el concepto de "índice" en el marco de la teoría de la agencia, véase Gell (2016, p. 44-45, 69-72 y 103-110).
} 
de la conquista funciona simplemente como indicador de heterodoxia, sin profundizar en la comprensión del significado de estos objetos sagrados. Así, según el documento que citamos más arriba, el indio se equivoca porque supuestamente venera el material del que están hechas las huacas, mientras que el cristiano venera aquello que la imagen representa ${ }^{10}$.

Ahora bien, no todas las piedras, ni todos los ríos, ni todos los objetos son huacas en el mundo andino. Esto quiere decir que no es solo la constitución material lo que hace de algo una huaca ( $\mathrm{y}$, por tanto, venerable), sino su lugar dentro de un determinado orden de cosas. Del mismo modo, el índice (que puede ser cualquier cosa), se constituye como tal cuando se convierte en un "nudo visible que une la red de relaciones dispersas en el espacio-tiempo social" (GELL, 2016, p. 99). Así entendida, la agencia es aquella trama de relaciones que se hace patente en esta cosa concreta: su determinada forma, color, tamaño, ubicación, etc., a partir de la cual se infiere la agencia.

Las huacas, en este sentido, antes que como ídolos funcionan como índices de una determinada relación entre los ámbitos de la naturaleza, lo humano, y lo divino, desplegando un campo de significación multidimensional, donde lo sensible y lo inteligible se encuentran compenetrados (ALLEN, 2015 , p. 35). Desde este punto de vista, la sensibilidad religiosa andina revela una concepción de lo sagrado rica y compleja que, dada su raíz matérico-sensorial, causa escándalo en la mente del conquistador, con una sensibilidad religiosa marcada por el pensamiento axiomático de la Escolástica (SIRACUSANO, 2005, p. 301).

La antropóloga Catherine Allen ha profundizado en la descripción de las huacas andinas como índices de agencia, sacando a la luz aspectos específicos de la sacralidad andina. Un primer elemento digno de consideración, es lo que podríamos llamar la matriz empírica de la cosmovisión andina. Así, conocer algo, más que establecer ciertos principios de validez universal, significa participar de un determinado "campo de visión" donde, junto con el punto de vista del sujeto cognoscente, comparece el punto de vista de los objetos conocidos (ALLEN, 2015, p. 25-28). La participación directa en este campo de visión es el principal criterio de validación del conocimiento, y todo lo que queda fuera de dicho campo solo puede conocerse de manera indirecta. En este sentido, el mundo o Pacha es un determinado punto de vista espacio-temporal, compuesto por diversas miradas que se afectan mutuamente $\mathrm{y}$, por tanto, una realidad dinámica y cambiante que jamás se podría reducir a algo así como un principio metafísico ${ }^{11}$.

\footnotetext{
${ }^{10}$ Como indica Siracusano, la huaca tendría una naturaleza reflexiva mientras que la imagen cristiana del conquistador tendría una naturaleza transitiva (SIRACUSANO, 2005, p. 267-276). 11 "In Sonqo I was told repeatedly that in a different sun there would be a different world and a different kind of people. To participate in a pacha-a living moment-is to share in its sut' $i$, its clarity (Allen 1994, 2011). Sut'i has as synonyms kunan ('now') and chiqaq ('true' or 'straight'). In the immediate moment one sees clearly and truly. In a different pacha there would be different light, and we would see differently" (ALLEN, 2015, p. 27).
} 
Las huacas, en este contexto, operan como demarcaciones que definen dicho campo de visión y, a su vez, en ellas se hacen presentes y perceptibles los diferentes órdenes que componen la realidad, toda ella preñada de un sentido sacro. De aquí se deriva un segundo aspecto de la cosmovisión andina, que nos permite ponderar con mayor profundidad su concepción de lo sagrado. Nos referimos al principio de reciprocidad que se reconoce entre los diferentes planos de la realidad: natural, humano y divino (ALLEN, 2015, p. 28-29; TOMICHÁ, 2013, p. 120-121). Más que una incapacidad de diferenciar y jerarquizar cada uno de estos planos, lo que sustenta la atribución de agencia a animales $\mathrm{u}$ objetos aparentemente inertes es la concepción del mundo o Pacha como una totalidad relacional, donde la "personalidad" no es atributo exclusivo de los seres humanos, sino que se encuentra "distribuida" en una red de relaciones (ALLEN, 2015, p. 26-27). Dicho de otro modo, cada ser participa de una "personalidad distribuida" que conecta al individuo con su Ayllú o comunidad, compuesta por sus coetáneos, sus antepasados y su territorio ${ }^{12}$.

Como se hace evidente, en el marco de la cosmovisión andina es insostenible la distinción taxativa entre lo sacro y lo profano. A este respecto, se hace especialmente interesante la concepción del quehacer humano como acción santificadora, de manera que aquel que alcanza destreza en el ejercicio de su oficio es llamado santuyuq o "poseído por lo santo" (ALLEN, 2015, p. 29). De este modo, por ejemplo, la producción de textiles es asumida como la creación de un ser vivo, con un cuerpo, un corazón y una boca, capaz de interactuar y comunicar mensajes de una cadena polifónica que interconecta diversos planos de realidad, de la que el/la artesano/a participa como un eslabón más ${ }^{13}$. A su vez, el color o la forma de las cosas no son "accidentes" de una esencia metafísica, sino que son portadores de un principio vital (espíritu o Ajayú) que se hace presente en personas, montañas y cosas, haciéndolos, por tanto, dignos de respeto

\footnotetext{
12 "Si la observamos desde esta perspectiva, la persona y la mente no se confinan a unas coordenadas espaciotemporales, sino que consisten en un abanico de sucesos biográficos y los recuerdos que generan, además de una categoría variada de objetos, rastros y restos materiales que se pueden atribuir al individuo. Estos, en conjunto, testimonian la agencia y el ser paciente durante una extensión biográfica que, de hecho, puede prolongarse mucho más allá de la muerte biológica. De esta manera, se comprende a la persona como la suma de los índices que demuestran, no solo en vida, la existencia biográfica de aquella. La agencia personal, como intervención en el entorno causal, crea un 'objeto distribuido', es decir, todas las diferencias materiales del 'modo en que son las cosas', de las que se pueden abducir una agencia particular" (GELL, 2016, p. 275).

${ }^{13}$ Sobre esto, subraya Allen: "This is not symbolism. The textile's personhood is not a symbolic correspondence in which textile stands for the person. It is more useful to think of the relationship in terms of 'distributed personhood.' This term was proposed by Alfred Gell, who held that the living quality of art objects derives from being 'enmeshed in a texture of social relationships' (1998:17) '... as social persons, we are present, not just in our singular bodies, but in everything in our surroundings which bears witness to our existence, our attributes, our agency' (ibid.:103)" (ALLEN, 2015, p. 31).
} 
y veneración (BOVISIO, 2018, p. 12-13). A la luz de estas consideraciones, se llega a plantear una concepción andina de la divinidad como "energía religadora" que, sin identificarse necesariamente con la materia, habita en ella y se comunica a través de ella, en aquellas cosas que son denominadas "huacas" (SIRACUSANO, 2005, p. 308) ${ }^{14}$.

Como se ha indicado, la mirada, en tanto que demarcación de un campo de visión -y de un campo de conocimiento-, sería el principal modo de agencia de la huaca. En este campo, que va definiendo a su vez un territorio sagrado, se despliega la energía religadora de la divinidad ${ }^{15}$. Si bien a la huaca se le atribuyen una serie de acciones milagrosas como el éxito de los cultivos o la buena fortuna en una determinada empresa (efectos que también se atribuyen a la imagen cristiana como mediadora del prototipo), lo que produce escándalo en la mente del conquistador es que la huaca pudiera hacer algo por sí misma, como si estuviera animada. De hecho, lo que conduce a catalogar a los pueblos indígenas como idólatras no es la creencia en los milagros, sino la supuesta incapacidad de distinguir entre las propiedades de un cuerpo animado y uno inerte. A este respecto, observa Gell, los pueblos que atribuyen agencia a sus objetos sagrados en los términos que hemos descrito son perfectamente conscientes de esta distinción, solo que en ciertos contextos los objetos inertes se constituyen en depósitos de la acción de la divinidad (GELL, 2016, p. 166-170) ${ }^{16}$.

Hay multitud de ejemplos en diversas culturas de agencia divina a través de la mirada, sobre todo en imágenes antropomórficas como las del hinduismo (GELL, 2016, p. 159-164). Referente a esto, puntualiza Gell:

Sean cuales sean los atributos que hacen religiosamente eficaces a los ídolos como locus para encuentros directos con las deidades, no se pueden confirmar ni refutar con pruebas físicas como la presencia de pulso, respiración, ingestión

\footnotetext{
${ }^{14}$ El teólogo boliviano Roberto Tomichá realiza una interpretación pneumatológica de este principio vital divino presente en todo lo creado, destacando que se trata de una "estrecha relación o reciprocidad entre el ser humano, Dios-Espíritu, y la naturaleza o entorno, reciprocidad considerada como 'realidad dinámica' siempre en movimiento" (TOMICHÁ, 2013, p. 121).

${ }^{15}$ Cabe destacar que, junto con atesorar el poder de lo sagrado y la memoria de los antepasados, las huacas articulan la enorme red vial del Tahuantinsuyo, fundamental para la subsistencia del inca (SIRACUSANO, 2005, p. 269). Como indica Allen, de este modo el territorio se convierte en un hogar: "Power and authority of places expand as their vision expands, with the greatest authority literally being the highest snowcapped peaks, who can see and be seen over the widest region; lower hills are visible over a smaller territory, and so forth, until one reaches the house (wasitira) at the most localized level." (ALLEN, 2015, p. 34). ${ }^{16}$ Véase también la observación de Wittgenstein respecto a las consideraciones de Frazer: "El disparate consiste, en este caso, en que Frazer lo presenta como si estos pueblos hubieran tenido una idea completamente falsa (incluso demente) del curso de la naturaleza, mientras que ellos solo poseían una interpretación curiosa de los fenómenos. Esto es, su conocimiento de la naturaleza, si lo hubieran puesto por escrito, no se habría diferenciado del nuestro de manera 'fundamental'. Solo su magia es distinta" (WITTGENSTEIN, 2016, p. 59).
} 
y eliminación, la habilidad para moverse o hablar, un rechazo natural por los ratones, etc. (GELL, 2016, p. 169)

Como destaca el antropólogo británico, este tipo de agencia atribuida a cosas que "miran" consiste en una agencia pasiva, como la de un invitado de honor al que se le atiende y del que no se espera que haga nada más que estar presente y disfrutar de su compañía (GELL, 2016, p. 172).

En el caso de las huacas, además, se da la particularidad de que no siempre se trata de objetos antropomórficos, como una imagen de Shiva, en la que se pueden identificar unos ojos como parte de un cuerpo antropomórfico. Montañas, ríos y estrellas también miran, entendiendo su "mirada" como un "acto de presencia", es decir, como un canal a través del cual se hace perceptible la energía religadora de la divinidad. Así pues, en este contexto hay que comprender la mirada no como atributo individual, sino como un modo de reciprocidad, es decir, que mi mirada se constituye también desde la mirada -y la escucha- del otro ${ }^{17}$. Dicho de otro modo, hay que asumir que en la cosmovisión andina conocer significa a su vez ser conocido, poseer y ser poseído. El tipo de agencia que se atribuye a la huaca, en este sentido, es perfectamente razonable y coherente con la ontología relacional del mundo andino, en tanto que no se le pide nada más que disfrutar de su presencia, que permanezca en su lugar y desde allí lo marque, definiendo las coordenadas de un campo de visión en el que participan y se comunican los órdenes de la naturaleza, lo humano y lo divino.

¿Es esta concepción de lo sagrado realmente opuesta a la doctrina cristiana? Sin lugar a dudas, es diferente a la de los conquistadores españoles del siglo XVI, ¿pero esto implica necesariamente que sea incompatible con la revelación de Dios en Jesucristo? ¿No se tratará, como enseña Evangelii nuntiandi (n. 63), de otro modo de orar, amar y considerar la vida, en el que Dios ya se manifestaba antes de la llegada de los españoles? El concepto teológico de "idolatría", que encuentra su fuente en el Antiguo Testamento, en ningún caso tiene como eje el desprecio de la materia, creación de Dios, sino que alude al empleo utilitario de su revelación, desnaturalizando su amor incondicional en función de nuestros propios intereses ${ }^{18}$. Este comportamiento idolátrico que denuncia la Biblia segu-

\footnotetext{
17 'I emphasized the role of vision partly because 'watching' and 'seeing' are culturally salient activities that lend themselves to a perspectivist account-we naturally associate perspective with vision. Implicit, however, in much of the material discussed here is the world-changing power of sound, especially speech. A fuller discussion would give equal time to aural perspectives" (ALLEN, 2015, p. 38).

${ }^{18}$ Véase, en particular, Dt 5 y 6, donde el tema de fondo es la fidelidad del ser humano a Dios. Como destaca Romano Guardini, en el Antiguo Testamento Dios siempre se hace presente -de manera, sin duda, misteriosa- a través de teofanías vinculadas a lugares, prácticas y objetos concretos (GUARDINI, 1965, p. 95-97).
} 
ramente se dio en el mundo religioso andino, pero también se reconoce en la avaricia y los atropellos del conquistador, así como en el corazón intransigente de tantas ortodoxias actuales.

Con todo, a pesar de los intentos de eliminar cada vestigio de la sensibilidad religiosa de los pueblos indígenas, muchos elementos de su concepción de lo sagrado perviven hasta nuestros días. En algunos casos de manera autónoma, como sistemas religiosos independientes del cristianismo, y, en otros, incorporándose a la milenaria tradición del evangelio inculturado. La imagen de culto latinoamericana, que, mucho más que una mera representación, reivindica aquella agencia divina que el indio reconocía en la huaca, es un ejemplo de esto último.

Ahora bien, el reconocimiento de una agencia -dicho teológicamentesacramental en la imagen de culto sigue siendo motivo de perplejidad para ciertos enfoques teológicos. Por lo pronto, como hemos señalado con anterioridad, se hace incompatible con el racionalismo extremo de ciertas mentalidades escolásticas. A su vez, teologías más receptivas a la representación sensible de Dios o a los aspectos contextuales del cristianismo, resuelven la ecuación entre imagen y prototipo a través de enfoques semióticos, sin abordar el problema de la agencia. Justamente, la cuestión teológica que plantea la imagen de culto latinoamericana no es la distinción entre imagen y prototipo como tampoco la legitimidad de su veneración y la incorrección de su adoración, sino el modo en que el prototipo se relaciona con la imagen y, eventualmente, si aquel está presente en ella.

\section{La imagen de culto cristiana: lugar de agencia sacramental}

Como es sabido, la doctrina cristiana sobre la imagen de culto se establece entre los siglos VIII y IX, en el marco de la denominada "querella iconoclasta". La enseñanza de la Iglesia acerca de la imagen fue establecida en el Segundo Concilio de Nicea (787) y es reconocida por buena parte de las confesiones cristianas ${ }^{19}$. En dicho concilio, se plantea la distinción

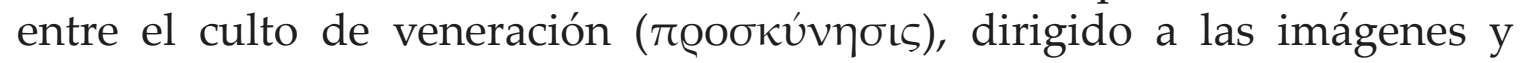
otros objetos empleados en la liturgia, y el culto de adoración ( $\lambda \alpha \tau \varrho \varepsilon i ́ \alpha)$, cuyo único destinatario debe ser el prototipo sagrado ${ }^{20}$. A esta distinción hace referencia el cura doctrinero cuando le aclara al indio que el cristiano no adora palos y maderas, sino al prototipo que está en el cielo, vivo y glorioso, "solamente pintado" en la imagen material.

\footnotetext{
${ }^{19}$ Véase CEC, n. 476-477 y n. 1159-1162.

${ }^{20} \mathrm{DH}, \mathrm{n}$. 601. Véase la misma definición en el Concilio de Trento (DH, n. 1823b).
} 
Esta distinción normativa a la que alude el cura doctrinero, no obstante, no es el corazón de la doctrina cristiana de la imagen ${ }^{21}$. Aun cuando aparentemente el principal motivo de la querella tiene relación con la legitimidad de producir y venerar imágenes y el modo en que hay que hacerlo, el tema de fondo de la discusión es cristológico ${ }^{22}$. Así, el cuestionamiento que plantean los iconoclastas no es sobre la existencia de imágenes, sino acerca de la legitimidad de representar a Cristo -hombre y Dios- en ellas, y el modo en que comparece -según su humanidad o según su divinidad. A este respecto, la declaración del Concilio es clara: Cristo comparece -está circunscrito- en la imagen según su humanidad ${ }^{23}$.

En la segunda etapa de la querella, que se desarrolla después del Concilio de Nicea, los iconoclastas insistirán en la inconveniencia de producir y venerar imágenes de Cristo, dado que, al representar solo su humanidad, se trataría de una representación incompleta de su persona teándrica, perfecto hombre y perfecto Dios (SCHÖNBORN, 1999, p. 154-158). Esta objeción retrotraerá la discusión al corazón mismo de la doctrina cristiana, que tiene relación con el misterio de la encarnación y, por tanto, con la explicación de la doble naturaleza de Jesucristo. ¿Las dos naturalezas de Jesucristo dan lugar a dos personas, una humana y otra divina? ¿La humanidad de Jesucristo es simplemente un recipiente de la divinidad, siendo finalmente absorbido por esta? Las respuestas a estas preguntas ya habían sido formuladas en los Concilios de Éfeso (432) y Calcedonia (451), donde se establece que las dos naturalezas de Jesucristo dan lugar a una sola persona, en la que ambas naturalezas se encuentran compenetradas,

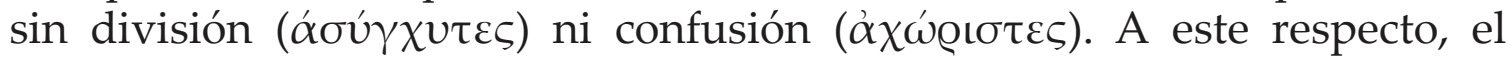
cardenal Christoph Schönborn puntualiza:

La gran paradoja de la revelación cristiana es que Dios mismo se ha hecho hombre y que su encarnación no representa una más, aunque sea la más grande, de las manifestaciones del Logos divino, una entre las muchas 'fulguraciones' del absoluto en la finitud: por el contrario, a partir de la encarnación existe una identidad real entre el Logos y un ser humano histórico, concreto. (SCHÖNBORN, 1999, p. 77)

En este sentido, la naturaleza humana de Jesucristo no es inferior a su naturaleza divina, así como su persona no es inferior a la persona del Padre, de quien es su imagen (Col 1,15). Como destaca Schönborn, a partir de aquí

el concepto de imagen experimenta una corrección cargada de consecuencias para la adecuada comprensión del arte: entre el arquetipo divino y la imagen

${ }^{21}$ Por lo demás, como ha sacado a la luz Hans Belting en su minucioso estudio sobre el culto de los íconos en la Antigüedad tardía y la Edad Media, es muy probable que el pueblo creyente cristiano no tuviera conciencia de estas sutilezas teológicas (BELTING, 2009). 22 "La lucha iconoclasta es, desde el punto de vista del contenido, la última fase de las controversias cristológicas de la Iglesia antigua" (SCHÖNBORN, 1999, p. 136).

23 "Si alguno no confiesa a Cristo nuestro Dios circunscrito [en la imagen] según la humanidad, sea anatema" DH, n. 607. 
divina no se da ningún desnivel de ser. En el contexto de la teología trinitaria, la noción de imagen pierde toda apariencia de inferioridad. (SCHÖNBORN, 1999, p. 23)

Evidentemente, una imagen pintada de Jesucristo no es lo mismo que la persona histórica de Jesucristo, que rió, lloró, padeció, y resucitó. Así, los teólogos de la imagen van a distinguir entre la imagen natural (el Hijo respecto al Padre), en que prototipo e imagen tienen una misma esencia, y la imagen artificial (la imagen pintada respecto a la persona histórica de Jesucristo), que tienen una esencia diferente (SCHÖNBORN, 1999, p. 185-188). Sin embargo, del mismo modo que Dios dignifica toda la humanidad en virtud de la encarnación, Jesucristo también dignifica su imagen pintada, convirtiéndola en lugar de revelación. En relación a esto, Teodoro Estudita, uno de los principales exponentes de la teología cristiana de la imagen, declara:

Lo que tú consideras inconveniente y vulgar, es -por el contrario- sublime y digno de Dios si lo consideras desde la grandeza del misterio. ¿Acaso no es un honor para el Altísimo rebajarse igual que los humildes se avergüenzan de ser enaltecidos? Así es también con Cristo: él habita en la altura de su divinidad caracterizada por la incircunscribilidad material, y sin embargo es su gloria haber descendido de un modo tan sublime hasta nosotros y haberse hecho en su propio cuerpo materialmente circunscribible. Él es materia, es decir, se ha hecho carne; él que da subsistencia a todo lo que existe no se avergüenza de haberse hecho lo que ha asumido (es decir, carne) y de ser también así llamado. (PG, n. 99, 336C apud SCHÖNBORN, 1999, p. 206).

Por tanto, que Dios mismo esté circunscrito en la imagen según su humanidad significa mucho más que estar "solamente pintado". Sin negar la distinción ontológica entre imagen y prototipo, Jesucristo no comparece en su imagen "solamente pintado", como si su humanidad corpórea manifestada en sus rasgos físicos fuera un accidente de su revelación. Como precisan los teólogos defensores de las imágenes, lo que comparece en la imagen de Jesucristo no es su naturaleza, ni humana ni divina, sino su persona, que tiene un rostro humano en el cual Cristo mismo se hace presente en virtud de la semejanza (PG, n. 99, 420D). Así, puntualiza Teodoro Estudita, la semejanza es un tipo de relación que salvaguarda, podríamos decir, una forma de presencia personal, que participa ( $\mu \varepsilon \tau \dot{\varepsilon} \chi \varepsilon \iota v)$ de la gracia y la gloria de Dios (PG, n. 99, 344BC).

¿Podríamos hablar en este caso también de una "persona distribuida", en el sentido de que objetos como las imágenes de Cristo, la cruz o los evangelios son depositarios de la acción redentora de Jesucristo, que se prolonga más allá de su muerte biológica, haciendo partícipe al creyente de la comunidad mística de la Iglesia? ${ }^{24}$. Si no creyéramos que Dios mismo

\footnotetext{
${ }^{24}$ Véase nota 14.
} 
glorificado se hace presente en su imagen, plantearán los teólogos defensores de las imágenes, pondríamos en duda su encarnación y, por tanto, que nuestra salvación se sustenta en el hecho de que Dios mismo se ha hecho carne y rostro, y que, en ese rostro concreto (no a pesar de él), se manifestó y se sigue manifestando en tanto que huella de su persona ${ }^{25}$.

A partir de aquí, pues, planteamos que la imagen de culto cristiana es depositaria de lo que podríamos llamar una "agencia sacramental" pues, en virtud de la encarnación, se constituye en un auténtico "índice" de la acción redentora de Jesucristo ${ }^{26}$. Independientemente de los vínculos que podemos establecer entre la teoría antropológica de la agencia y la teología de la imagen en términos generales, se hace especialmente sugerente el paralelismo entre el modo en que opera la agencia sacramental en la imagen de culto y la agencia de lo sagrado en la huaca prehispánica.

En efecto, si tuviéramos que señalar cuál es el principal modo de agencia de la imagen de culto cristiana, tendríamos que decir que es la mirada. En este sentido, es significativo que el principio fundamental de la composición en la pintura cristiana prerrenacentista sea justamente la denominada "perspectiva invertida" o "perspectiva relacional", consistente en proyectar el campo de visión de la imagen al espacio del espectador ${ }^{27}$. A su vez, reforzando esta idea, se hace especialmente relevante que la arquitectura cristiana se desarrollara en función de la ubicación de determinados programas iconográficos, coronando el espacio del templo la mirada de Jesucristo Pantocrátor desde la cúpula, o que los iconostasios que se disponen en los hogares del pueblo creyente estuvieran ubicados en el vértice de la habitación -el "rincón de la belleza"-, dado que es el único punto desde el cual se domina todo el espacio con la mirada. Ninguna de estas operaciones tendría sentido si la imagen no detentara el poder de la mirada y definiera un campo de visión, en el cual despliega su bendición.

Mucho más que tratarse de una biblia de los pobres, la imagen de culto cristiana reivindica una capacidad performativa propia a través de la mirada, la posibilidad de una autotestificación divina complementaria a la proclamación de la Palabra, las definiciones doctrinales, y la catequesis. Así, en la obra de Juan Damasceno encontramos variadas referencias a

\footnotetext{
25 “Encarnación no significa solamente que el Hijo tiene también su humanidad, sino que él es hombre, y este hombre" (SCHÖNBORN, 1999, p. 106).

${ }^{26}$ Véase SC, n. 7. "La imagen de culto contiene algo incondicionado. Está en relación con el dogma, con el Sacramento, con la realidad objetiva de la Iglesia. Se podría comprender que el artista que quiere producir imágenes de culto requiriera una ordo, una ordenación y misión por parte de la Iglesia [...] En la imagen de culto se prolonga el Sacramento, el opus operatum de la gracia. A ella se acerca el creyente como a un poder sagrado" (GUARDINI, 1960, p. 23-24).

${ }^{27}$ Véase Aguirre (2018, p. 170- 200).
} 
cómo las imágenes de los santos acompañan con su mirada la meditación que realizan los teólogos sobre el texto sagrado, como si estuvieran presentes $^{28}$. La negación de esta irrupción de la gracia divina en la materia, para los teólogos defensores de las imágenes, atentaría contra el corazón de las definiciones dogmáticas de la Iglesia respecto a Jesucristo ${ }^{29}$. Este principio de autotestificación divina que define todo signo sacramental, como destaca Romano Guardini, se encuentra presente en la mayor parte de las culturas torpemente calificadas como "primitivas":

Para ellos, toda cualidad, toda relación, toda cosa, todo orden de vida son de tal índole, que consisten y son aprehendidos, no de manera 'natural' ni tampoco 'cultural', en el sentido nuestro, sino de manera 'religiosa', es decir, dentro de un fluido religioso que traspasa todo, dentro del 'Mana'. Sólo más tarde tiene lugar el giro funesto, por el cual los actos culturales -como el conocer, el obrar, el crear- se separan de ese contexto, y el acto religioso se convierte en una actividad especial. Lo cultural se vuelve entonces independiente, llena la conciencia, empuja a lo religioso a un segundo plano, y lo que antes estaba dado de manera primaria se convierte ahora en lo desvelado. (GUARDINI, 1965, p. 45)

En el marco de la epistemología sacramental de Guardini, probablemente el teólogo católico contemporáneo que más profundamente ha comprendido la dimensión sacramental de la imagen de culto cristiana, encontramos una clave fundamental para ponderar con mayor profundidad el vínculo entre la agencia sacramental de la imagen y la agencia sagrada de la huaca. En ambos casos reconocemos un principio de reciprocidad que relaciona los diversos planos de la realidad, y que hace del mundo un lugar santificado. Así, el autor alemán subraya que la condición de criatura -y, por tanto, el poder creador de Dios que sostiene permanentemente la creación- no es algo así como un principio metafísico, sino una energía que se ve y se hace presente en la materia (GUARDINI, 1965, p. 35).

Ver -y conocer-, en este sentido, no significa situarse en una situación de dominio de la realidad, sino introducirse en el "campo de fuerzas" de lo observado, iniciándose un diálogo con las cosas que va mucho más allá de las fronteras de la razón (GUARDINI, 1965, p. 32-33). “'Ver' -o tal vez debamos decir, más exactamente, 'mirar'- significa por lo pronto,

\footnotetext{
${ }^{28}$ Refiriéndose a Juan Crisóstomo, Damasceno relata que "mientras leía las epístolas de Pablo, contemplaba la imagen y se fijaba en él como si estuviera vivo, llenándolo de felicidad, y tenía todo su pensamiento dirigido a él mientras lo imaginaba, y se comunicaba con él a través de la mirada" (PG, n. 99, 1277C).

${ }^{29}$ Así, Damasceno afirma que "[además de los íconos] respeto el resto de la materia y la considero sagrada en tanto que a través de ella tuvo lugar mi salvación, a través de materia que está llena de gracia y acción de Dios" (PG, n. 99, 1241B). Véase también: "La encarnación de Dios es la prueba de que el fin último de la contemplación cristiana no puede ser una visión puramente espiritual: Si ésta fuera suficiente por sí misma, entonces habría sido suficiente que la Palabra eterna viniera a nosotros de modo puramente espiritual" (SCHÖNBORN, 1999, p. 203).
} 
y de manera radical, ser afectado por la aparición sensible del objeto y ser invitado a comprender su contenido" (GUARDINI, 1965, p. 27). El Dios del cristianismo no ha querido sustraerse de este campo de fuerzas sensibles; antes bien: lo sustenta y lo extiende, inaugurando a través de la encarnación una nueva creación ${ }^{30}$.

Dentro de las cosas creadas, la imagen de culto -como la huaca- ocupa un lugar especial. Como hemos descrito más arriba, la imagen de culto también define un campo de visión donde Dios ya no solo se manifiesta, como en toda la creación, sino que además se personifica. Asume un rostro concreto, marca el espacio con su mirada, y a través de ella santifica el mundo. Como subraya Guardini, "El sentido de la imagen de culto es que Dios se haga presente [...] De lo que se trata es de una forma propia de presencialización, que no se puede derivar de otras: la presencia de la imagen sagrada" (GUARDINI, 1960, p. 21). Entonces, nos volvemos a hacer eco de la pregunta del indio a la luz de lo expuesto hasta aquí: ¿estas no son huacas también, como las nuestras?

\section{Conclusiones: una fe con rostro andino}

En el relato del viaje misionero de Pablo a Atenas, se plantea un interesante gesto evangelizador: habiendo elogiado el respeto de los paganos por las cosas divinas, el apóstol hace referencia a un altar que vio durante su recorrido por la ciudad, en el que estaba inscrita la frase "al dios desconocido" $\mathrm{y}$, dirigiéndose al pueblo ateniense, les dice: "a este que adoran sin conocer les vengo a anunciar yo" (Hc 17,23). Como es sabido, el cristianismo pasa de ser una secta judía a configurarse como una nueva religión justamente a través de su encuentro con la cultura griega: su filosofía, sus imágenes, sus instituciones. Esta inculturación del evangelio en el mundo griego, que se termina de consolidar al menos tres siglos después del anuncio de Pablo y que hoy vemos con absoluta naturalidad, es el mismo proceso al que asistimos repetidas veces a lo largo de la historia: en el Imperio Romano, en los pueblos francos y visigodos, en los pueblos eslavos, etc.

Cada uno de estos procesos de inculturación del evangelio ha tenido características propias, incluyendo, lamentablemente la mayoría de las veces, actos de coerción y violencia por parte de los supuestos portadores de la Buena Nueva. A pesar de esto, sin embargo, en un proceso dinámico mar-

\footnotetext{
${ }^{30}$ Véase 2 Cor 5, 17 y Ap 21, 1-7. "El cristiano no ha retirado su obediencia a Dios, pero sí ha permitido, en gran parte, que el Dios vivo que se manifestó en la Revelación se convirtiese en el abstracto 'Dios de los filósofos', en el 'señor absoluto' de la metafísica [ ] El pensamiento cristiano tiene, pues, la tarea de llegar de nuevo hasta el orden vivo que se manifiesta en la revelación" (GUARDINI, 1965, p. 17-18).
} 
cado por la libre acción del Espíritu, los pueblos de la tierra han terminado apropiándose del cristianismo, dándole sentido desde su propia cultura, y enriqueciendo su milenaria tradición. Es fundamental, en este sentido, comprender que para el cristianismo el evangelio no es una suerte de manifiesto programático o una mera información, sino un acontecimiento cultural, una orientación de la vida que se encarna en las culturas y no a pesar de ellas; como afirma Francisco, "La gracia supone la cultura y el don de Dios se encarna en la cultura de quien lo recibe" (EG, n. 115).

En el caso de América, si bien en cada contexto y época se dio de manera diferente y heterogénea, se reconocen tres momentos en el proceso de evangelización: en una primera instancia (sobre todo durante el último cuarto del siglo XVI), se aspira a arrasar y destruir todo lo relativo a la sensibilidad religiosa local; a continuación, tomando conciencia de lo infructuoso de dicha empresa, se reconoce un intento por comprender la lógica interna de aquellas prácticas que, a su vez, son menos extrañas para la población africana que llega a América y las masas populares que van engrosando la migración española; finalmente, se da lugar a un proceso de negociación, que tiene como resultado la aparición de la imagen de culto latinoamericana ${ }^{31}$.

Si comparamos este proceso con el gesto evangelizador de Pablo ante el pueblo ateniense, podemos reconocer una diferencia significativa: Pablo no es representante de una empresa conquistadora. Esto tiene un impacto directo en el modo en que Pablo plantea su anuncio: reconoce que el pueblo griego ya tiene una experiencia de Dios y busca en sus objetos y prácticas un referente para hablar del evangelio de Jesucristo. En este sentido, el "ídolo" pagano no opera como un obstáculo para el anuncio del evangelio, sino como un lugar de enunciación que, con el paso del tiempo, dará origen a la imagen de culto cristiana. Como hemos expuesto en el presente artículo, nosotros reconocemos un proceso análogo respecto a la huaca prehispánica: reconocemos en ella una semilla del verbo.

En ningún caso pretendemos afirmar que la huaca prehispánica sea lo mismo que la imagen de culto cristiana. Además de ser absolutamente inexacto, afirmar algo así sería incurrir en un nuevo gesto colonizador. Por otro lado, la agencia, como término antropológico, apunta a describir un fenómeno presente en muchas culturas de modos diferentes, mientras que el término teológico de sacramento busca comprender la revelación de Dios en Jesucristo. El relato de la encarnación y la ontología de la persona que se deriva de él constituyen una explicación de la agencia de lo sagrado distinta a la que los pueblos prehispánicos hayan podido elaborar desde su propia cosmovisión. En este sentido, consideramos fundamental

\footnotetext{
${ }^{31}$ Véase Siracusano (2005, p. 301-302). Serge Gruzinski, en su análisis del surgimiento de la imagen de la Virgen de Guadalupe que plantea como caso paradigmático de este proceso, señala que ya hacia mediados del siglo XVII podemos hablar de una imagen de culto latinoamericana (GRUZINSKI, 1994, p. 102-159).
} 
distinguir aquella base antropológica común a la imagen y la huaca de la explicación "teológica" que cada tradición concreta elabora sobre sus objetos y prácticas religiosas.

Ahora bien, esta base antropológica común abre un horizonte totalmente diferente para interpretar el resultado de la evangelización en América Latina $^{32}$. En primer lugar, nos permite darnos cuenta de que los pueblos andinos ya tenían una experiencia del Dios de la vida antes de la llegada del cristianismo, como Pablo afirmara de los atenienses; en segundo lugar, nos provee de una explicación sobre el hecho de que la imagen "solamente pintada" del conquistador se haya convertido en una imagen que se comunica con su pueblo; en tercer lugar, nos lleva a reconocer en el cristianismo latinoamericano una nueva inculturación del evangelio (más que un sincretismo), ni mejor ni peor que otras, sino solamente enraizada en una tradición cultural diferente a la de la cultura europea.

Como señala Pablo VI en Evangelii Nuntiandi, comprender el evangelio como una realidad mediada por la cultura es una tarea ardua y delicada, que implica tener siempre presente la especificidad del misterio de la revelación de Dios en Jesucristo, pero también la pluralidad de su realización histórica. En este sentido, el papa que abre las puertas a la relectura de la llegada del evangelio a América, subraya que "La evangelización pierde mucho de su fuerza y de su eficacia, si no toma en consideración al pueblo concreto al que se dirige, si no utiliza su 'lengua', sus signos y símbolos, si no responde a las cuestiones que plantea, no llega a su vida concreta" (EN, n. 63).

\section{Abreviaciones}

$$
\begin{aligned}
& \mathrm{CEC}=\text { Catecismo de la Iglesia Católica } \\
& \mathrm{DH}=\text { DENZINGER } \\
& \mathrm{EG}=\text { Evangelii gaudium } \\
& \mathrm{EN}=\text { Evangelii nuntiandi } \\
& \mathrm{FT}=\text { Fratelli Tutti } \\
& \mathrm{GS}=\text { Gaudium et spes } \\
& \mathrm{NA}=\text { Declaración Nostra aetate } \\
& \mathrm{PG}=\text { Patrologiae Cursus completus } \\
& \mathrm{SC}
\end{aligned}
$$

\footnotetext{
${ }^{32}$ No se trata de situarnos en una posición de superioridad frente al español del siglo XVI, que vive en un mundo donde el cristianismo se ha convertido en Cristiandad, sino de interpretar la evangelización a la luz de los desarrollos del Concilio Vaticano II y las teologías contextuales.
} 


\section{Referencias}

AGUIRRE, F. Arte y teología: el renacimiento de la pintura de íconos en Grecia moderna. Santiago de Chile: UC, 2018.

AGUIRRE, F. La lógica estético-sacramental de la fiesta religiosa. Alpha, Osorno, n. 53, 2021. (en prensa)

ALLEN, C. The Whole World Is Watching: New Perspectives on Andean Animism. In: BRAY, T. (Ed). The Archaeology of Wak'as: Explorations of the Sacred in the Pre-Columbian Andes. Colorado: University Press of Colorado, 2015. p. 23-46.

BELTING, H. Imagen y culto: una historia de la imagen anterior a la edad del arte. Madrid: Akal, 2009.

BOVISIO, M. A. ¿Qué cosa es eso que llaman "color"? Reflexiones en torno a las concepciones andinas sobre el color y su contrapunto con las del Occidente moderno. Caiana, Buenos Aires, n. 13, p. 1-16, 2018.

CAAMAÑO, J. C. Rostro de la eternidad: imagen, conocimiento y condición simbólica. Teología, Buenos Aires, v. XLII, n. 86, p. 109-140, 2015.

CARAM, M. J. El Espíritu en el mundo andino: una pneumatología desde los Andes. Cochabamba: Verbo Divino, 2012.

CASTRO, V. De ídolos a santos: evangelización y religión andina en Los Andes del sur. Santiago de Chile: DIBAM, 2009.

CATECISMO DE LA IGLESIA CATÓLICA, Santa Fe de Bogotá: San Pablo, 2000.

CODINA, V. La religión del pueblo: de cuestionada a interpelante. Cantabria: Sal Terrae, 2019.

CONCILIO VATICANO II. Madrid: BAC, 1965.

DENZINGER, H. J., El magisterio de la Iglesia: manual de los símbolos, definiciones y declaraciones de la Iglesia en materia de fe y costumbres. Barcelona: Herder, 1963.

FERNÁNDEZ, E. La Cosecha: teología hispana contemporánea en EE.UU. (19722019). Santiago de Chile: Ediciones Universidad Alberto Hurtado, 2020.

FRANCISCO, Papa. Evangelii gaudium: exhortación apostólica sobre el anuncio del evangelio en el mundo actual. Santiago de Chile: Conferencia Episcopal de Chile, 2013.

GELL, A. Arte y agencia. Buenos Aires: Sb, 2016.

GRUZINSKI, S. La guerra de las imágenes: de Cristobal Colón a "Blade Runer" (1492-2019). México D.F.: FCE, 1994.

GUARDINI, R. Imagen de culto e imagen de devoción. In: GUARDINI, R. La esencia de la obra de arte. Madrid: Guadarrama, 1960. p. 15-35.

GUARDINI, R. Los sentidos y el conocimiento religioso. Madrid: Cristiandad, 1965.

IRARRÁZABAL, D. Teología en la fe del pueblo. San José de Costa Rica: DEI, 1999.

MILLONES, L. De la evangelización colonial a la religiosidad popular peruana: el culto a las imágenes sagradas. Sevilla: Fundación El Monte, 1998. 
MORGAN, D. Images at Work: the Material Culture of Enchantment. Oxford: Oxford University Press, 2018.

PAULO VI, Papa. Evangelii nuntiandi: exhortación apostólica sobre la evangelización en el mundo contemporáneo. Santiago de Chile: San Pablo, 1994.

PEIRCE, Ch. S. La ciencia de la semiótica. Buenos Aires: Nueva Visión, 1986.

SCHÖNBORN, C. El ícono de Cristo: una introducción teológica. Madrid: Encuentro, 1999.

SIRACUSANO, G., El poder de los colores: de lo material a lo simbólico en las prácticas culturales andinas (siglos XVI-XVIII). Buenos Aires: FCE, 2005.

TOMICHÁ, R. Teologías amerindias: Balance y tareas pendientes. Yachay, Cochabamba, v. 30, n. 57-58, p. 127-152, 2013.

WITTGENSTEIN, L. Observaciones sobre la rama dorada de Frazer. Santiago de Chile: Tácitas, 2016.

Artículo sometido en 12.06.2021 y aprobado en 01.11.2021.

Federico Aguirre Doctor en Culturas y Lenguas del Mundo Antiguo por la Universidad de Barcelona y Magister en Teología por la Universidad de Atenas. Académico y Vicedecano de la Facultad de Teología de la Pontificia Universidad Católica de Chile. Investigador del Centro de Estudios de la Religión. Orcid.org/0000-0001-7203-7863. E-mail: federico.aguirre@uc.cl

Dirección: Av. Vicuña Mackenna 592, depto. 216,

Providencia, Santiago, Chile 